\title{
The neuritogenic and neuroprotective potential of senegenin against $A \beta$-induced neurotoxicity in PC 12 cells
}

\author{
Robert Jesky and Hailong Chen*
}

\begin{abstract}
Background: Improved therapeutics aimed at ameliorating the devastating effects of neurodegenerative diseases, such as Alzheimer's disease (AD), are pertinent to help attenuate their growing prevalence worldwide. One promising avenue for such therapeutics lies in botanical medicines that have been efficaciously employed in the likes of traditional medicine doctrines for millennium. Integral to this approach is the necessity of neuritogenesis and/or neuroprotection to counterbalance the deleterious effects of amyloid- $\beta(A \beta)$ proteins. Senegenin, a principle saponin of Polygala tenuifolia Willd., which has empirically shown to improve cognition and intelligence, was chosen to evaluate its cytoprotective potential and possible neuritogenic and neuroprotective effects.

Methods: The purpose of the present study was then to analyze morphological changes in neurite development and altered protein expression of two proteins requisite to neuritogenesis, growth associated protein 43 (Gap-43) and microtubule-associated protein 2 (MAP2) in PC 12 cells. Neuritogenic analysis was conducted with immunofluorescence after incubation with $A \beta_{(25-35)}$ peptide, and to deduce information on cell viability and mitochondrial functionality MTT (3,(4,5-dimethylthiazol-2-yl)2,5-diphenyltetrazolium bromide) was employed.

Results: This study found that cells pre-incubated with senegenin for $24 \mathrm{~h}(40 \mu \mathrm{g}$ and $20 \mu \mathrm{g} / \mathrm{ml})$ before introducing $A \beta$ attenuated $A \beta$-cytotoxicity, and significantly increased cell viability by $23 \%$ and $34 \%(P<0.001)$, respectively. In neurite outgrowth experiments, $A \beta$ was compared to NGF positive control and senegenin treated groups which showed a drastic decrease in the quantity, average length and maximum length of neurites $(P<0.001)$. At concentrations of $1 \mu \mathrm{g} / \mathrm{ml}(P<0.01)$ and $5 \mu \mathrm{g} / \mathrm{ml}(P<0.05)$ senegenin triggered neuritogenesis with significant increases in total neurite number, average length and maximum length. This was additionally shown through the augmented expression of MAP2 and Gap-43.
\end{abstract}

Conclusions: These results suggest that senegenin possesses cytoprotective properties, can moderate neurite outgrowth and augment MAP2 and Gap-43, thus suggesting a potential therapeutic value for Polygala tenuifolia in neurodegenerative disorders.

Keywords: Neuritogenesis, Neuroprotective, Nootropic, Cytotoxicity, PC 12 cells, Senegenin

\footnotetext{
* Correspondence: hailongchen2007@hotmail.com

Department of General Surgery-Integrated traditional Chinese and Western

medicine, 1st Affiliated Hospital of Dalian Medical University, No. 222,

Zhongshan Road, Xigang District, Dalian 116011, China
} 


\section{Background}

A major factor precipitating the pathogenesis of neurodegenerative illnesses such as Alzheimer's and Parkinson's disease is misfolded proteins, particularly amyloids. Neurons are highly susceptible to the deleterious effects of misfolded proteins which are prone to aggregate when large accumulations arise [1]. The pernicious effects of amyloid- $\beta$ (A $\beta)$ constitute one of the hallmarks of Alzheimer's disease (AD). Alzheimer's disease, a progressive neurodegenerative illness, characteristically results in severe cognitive deficits. The progressive cognitive decline associated with $\mathrm{AD}$ is attributable to dystrophic neurites and neuronal atrophy, which are the corollaries of extracellular amyloid- $\beta$ peptide $(\mathrm{A} \beta)$ deposition and the intracellular deposition of neurofibrillary tangles (NFT) [2]; the latter of which is comprised of hyperphosphorylated tau proteins, and posited to be the resultant effect of the toxic cascade initiated by $A \beta$. The neurotoxic properties of $A \beta$ have thus been formulated in an amyloid cascade hypothesis which posits that aggregates of $A \beta 42$ accumulate into senile plaques, either triggering complement factors and cytokines or directly leading to synaptic degeneration bypassing the activation of complement factors and cytokines, continually proceeding to alter ionic homeostasis and kinase activity. Ultimately, progressive neuritic dysfunction, cell death and neurotransmitter deficits result [3]. Current postulates, however, now strongly support the notion that the initial memory loss seen in $\mathrm{AD}$ directly correlates to oligomeric forms of $\mathrm{A} \beta$, which precipitate synaptic deterioration [4-7]. Therefore, with the incidence of $\mathrm{AD}$, the most common form of dementia, steadily on the rise, and a global prevalence predicted to affect over 80 million people by 2040 [8], the development of efficacious therapeutics aimed at abating AD pathogenesis, most notably neuritic and synaptic regeneration, is a necessity. Deciphering the complexities of AD stands at the forefront of neuroscience, with extensive research efforts demonstrating that $A \beta$ is neuro-and synapto-toxic in both in vitro and in vivo experiments. Various research models have employed the use of the $A \beta$ (25-35) peptide, which retains the toxic properties of the full length peptide (39-43), to test the pathogenic mechanisms of $\mathrm{A} \beta$, making it a desirable model for testing $\mathrm{AD}$, and thus chosen for the present study to examine its toxicity in a neuronal cell line.

The PC 12 cell line, originally obtained from a transplantable rat pheochromocytoma [9], has become a widely used neuronal model to test neurotoxins implicated in neurodegenerative disorders, notably $\mathrm{A} \beta$. It has additionally proven to be advantageous in expanding current understandings of what cellular proteins/mechanisms drive neurite growth. In the presence of neurotrophic factors, namely nerve growth factor (NGF), PC 12 cells cease division, and differentiate into sympathetic-like neurons producing long neurites $[9,10]$. Upon differentiation PC 12 cells begin to express several integral proteins responsible for neurite growth [11, 12]. Growth associated protein 43 (Gap-43), a major polypeptide localized in the growth cone [13], is required for growing neuronal processes during development and regeneration [14]. Induction of Gap- 43 by NGF has been reported to take place within $24 \mathrm{~h}$, and is a prerequisite of neurite outgrowth in PC 12 cells [15]. Gap-43 is thus an essential protein imperative to the various stages underlying neural plasticity with a strong correlation to the growth phase of neurons, making it a good indicator of regeneration. Moreover, plasticity alterations in the brain evidently require the polymerization of microtubules, which play a paramount role in neuronal growth processes $[16$, 17], and intracellular signaling, with an integral relationship to MAPs that are mobilized during dentritic and axonal development. Microtubule-associated proteins (MAPs) regulate tubulin polymerization and are cardinal in microtubule assembly [11]. MAP2 shares a reciprocal relationship with mitogen-activated protein kinases (MAPKs) by being a cognate substrate. MAPKs NGFstimulated activities and its association with phosphorylation states putative to neuritogenesis $[18,19]$ illustrate that MAPK is a pertinent cellular component of MAP2 function. Induction of neurite growth in PC 12 cells appears to be dependent upon the activation of MAPK, in that the inhibition of MAP kinase completely blocks NGF-induced neurite growth. Similarly, brief activation of MAP kinase by other growth factors has been shown to result in reduced PC 12 differentiation [20]. Not surprisingly, PC 12 neurite outgrowth requires similar intracellular mechanisms as hippocampal neurons, for instance, those that drive microtubule assembly and trigger MAPs $[17,21]$. Another indispensable component of neuronal functionality, and imperative for neuritic regeneration, is the requisite synaptic terminal and its vesicles, both of which are additionally expressed PC 12 cells [22].

A novel approach to tackling the complexities of neurodegenerative disorders lies in the plasticity of the brain, which undergoes continued functional and structural alterations throughout life [23, 24]. Extensive research has shown that long after postnatal development the brain continues to birth new neurons (neurogenesis), primarily in the dentate gyrus of the hippocampus $[25,26]$, a structure well known for memory processing. Influential factors that contribute to neural plasticity are continuously being elucidated, with paramount importance being the natural, endogenous structural adaptations induced through neurotrophins. To date, various neurotrophins, including NGF, have proven to be efficacious in increasing synaptic efficacy, promoting neuritogenesis, synaptogenesis, and neuronal survival [27-30]. The use of neurotrophins as therapeutic agents, however, 
is limited since due to their molecular structure they don't readily cross the blood brain barrier [31-34]. Therefore, exogenous substances that either trigger neurotrophins or independently contribute directly or indirectly through intracellular signaling mechanisms to neurito-and-synaptogenesis are likely to be an essential element of future therapeutics that halt neurodegeneration. Numerous plant sources have congruently been shown to possess nootropic activity and promote functional and structural changes in various cell types.

The root of Polygala tenuifolia Willd. has been used for more than a millennia in traditional Chinese medicine for the treatment of memory loss associated with aging, forgetfulness and amnesia. Several of the most commonly used empirical traditional Chinese medicine formulas aimed at improving cognition contain Polygala tenuifolia [35]. Biochemical analysis has ascertained that the active components of P. tenuifolia are primarily saponins that are derivatives of presenegenin. Current research efforts directed towards elucidating the therapeutics of P. tenuifolia have shown that it possesses both neuroprotective and nootropic activity, exemplified in its ability to effectively attenuate scopolamine-induced memory impairments [36, 37], decrease $A \beta$ secretion $[38,39]$, up regulate neurotransmitters [40], and increase NGF secretion is cultured astrocytes [41]. In addition, P. tenuifolia has been shown to promote the proliferation of hippocampal stem cells and neurite outgrowth [42], demonstrating that it's a promising agent in the amelioration of neurodegeneration. Therefore, the aim of this research was to explore the potential neuroprotective and neuritogenic properties of senegenin (Fig. 1), a component of P. tenuifolia root extracts, on $A \beta{ }_{(25-35)}$-induced cyto-and-neurito-toxicity in differentiated PC 12 cells.

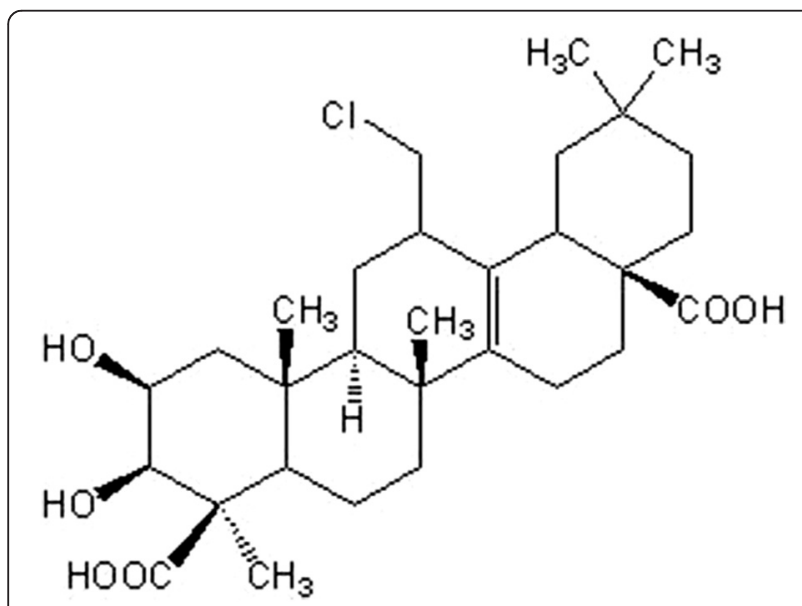

Fig. 1 Chemical structure of Senegenin

\section{Methods}

\section{Materials}

$\mathrm{A} \beta$ (25-35) peptide fragment, poly-D-lysine, and 3-(4,5dimethylthioazol-2-yl) 2,5 diphenyltetrazolium bromide (MTT) were all obtained from Sigma Chemical Co., (St. Louis, USA). Dimethyl sulfoxide (DMSO) was purchased from AMRESCO, (Solon, OH, USA). Mouse $\beta$-NGF was purchased from PeproTech Asia, (Rehovot, Israel). All tissue culture agents were purchased from Thermo Scientific Hyclone (Utah, USA). Senegenin - CAS No.667438-01-9, $>98 \%$ HPLC) was obtained from Mansite Pharmaceutical Co., LTD. (Chengdu, China).

\section{Cell culture}

PC 12 cells were obtained from Shanghai Institute for Biological Science Cell Bank, CAS, (Shanghai, China) and maintained in high glucose Dulbecco's Modified Eagle Medium (DMEM) supplemented with $5 \%(\mathrm{v} / \mathrm{v})$ heat-inactivated horse serum, $5 \%(\mathrm{v} / \mathrm{v})$ heat-inactivated fetal bovine serum, a mixture of $1 \%$ penicillin/streptomycin and incubated in an atmosphere with $5 \% \mathrm{CO} 2 /$ $95 \%$ humidified air at $37^{\circ} \mathrm{C}$. Cells were kept in $25 \mathrm{~cm}^{2}$ cell culture flasks (Corning Incorporated, USA) and dissociated every 3-4 days. Prior to all treatments cells were plated on either poly-D-lysine-coated 96-well microplates (Corning Incorporated, USA) or $1.8 \mathrm{~cm}^{2}$ glass cover slips to facilitate PC 12 differentiation. PC 12 cell differentiation was induced with differentiating medium (DM) which was comprised of DMEM, $1 \%$ donar equine serum, $1 \%$ penicillin/streptomycin, and $100 \mathrm{ng} / \mathrm{ml}$ mouse $\beta$-NGF. Every 3-4 days half of the differentiating medium was changed and replaced with fresh DM. All cells tested in this experiment underwent differentiation prior to evaluation.

\section{Cell viability assay}

Cell viability was determined by MTT (3,(4,5-dimethylthiazol-2-yl)2,5-diphenyltetrazolium bromide) to provide information on cell viability and mitochondrial functionality. Cells were seeded at a density of $1 \times 10^{4}$ in $100 \mu \mathrm{l}$ DM (NGF $100 \mathrm{ng} / \mathrm{ml}$ ) onto 96-well poly-D-lysine-coated plates for 4 days to facilitate neurite growth. After 4 days, cells were pre-treated with or without senegenin for $24 \mathrm{~h}$, followed by incubation with $A \beta_{(25-35)}$ peptide for another $24 \mathrm{~h}$. Prior to use, $A \beta_{(25-35)}$ was incubated at $37{ }^{\circ} \mathrm{C}$ for 4 days to allow aggregation. After incubating MTT $(20 \mu \mathrm{l})$ for $4 \mathrm{~h}$ at $37{ }^{\circ} \mathrm{C}$ the formazan crystals were lysed in $150 \mu \mathrm{l}$ dimethyl sulfoxide (DMSO), and the microplates were shaken vigorously to ensure complete solubilization. The optical density was $584 \mathrm{~nm}$ and read/ determined in a Miltiskan MK 3 reader (Thermo Lab Systems Beverly, MA, USA). All values were presented as means \pm SEM of numbers obtained from 6 wells, from 3 separate experiments, and cell viability (\%) 
was expressed as a percentage relative to the NGFtreated control cells.

\section{PC12 neurite outgrowth experiments}

Coated $18 \times 18 \mathrm{~mm}$ coverslips pretreated with poly-Dlysine were placed into six-well culture plates and PC 12 cells were then plated at a density of $1.4-1.6 \times 10^{4}$ in $1.5 \mathrm{ml}$ cell suspension per well in the presence of DM to allow for differentiation. The plates were maintained in a homeostatic environment (see above) and half of the DM was changed every 3-4 days. Upon 7 days of differentiation, $A \beta(10 \mu \mathrm{M})$ was added for 4 days to measure the effects of neuritic degeneration. Subsequently, 4 days after $A \beta$ treatment the medium was removed and replaced with fresh medium containing NGF with or without various concentrations of senegenin to measure potential neurite regeneration. Moreover, the application of neurite specific antibodies (GAP-43 (1:100), MAP2 (1:50)), were used as markers of neurite growth formation, respectively. For this study, neurites were defined as processes nothing less than $10 \mu \mathrm{m}$ or equal to the diameter of the cell body. Morphological observation of neurite outgrowth was characterized by three different parameters: average neurite length, maximum neurite length and neurite quantity. Neurite outgrowth parameters were quantified by visual counting and manual tracing, and acquired through confocal microscopy.

\section{Immunfluorescence}

Cells were plated at a density of $1.4-1.6 \times 10^{4}$ on poly-Dlysine-coated $18 \times 18 \mathrm{~mm}$ coverslips in six-well culture plates ( $1.5 \mathrm{ml}$ cell suspension per well). Differentiated cells were fixed in paraformaldehyde for $15 \mathrm{~min}$ at room temperature, succeeded by $10 \mathrm{~min}$ fixation with ice cold acetone at $-20{ }^{\circ} \mathrm{C}$, followed by several rinses with PBS. Non-specific binding in $5 \%$ goat serum and $0.2 \%$ Triton X-100 (BioSource Invitrogen, Carlsbad, CA, USA) preceded incubation with antibodies against Gap-43, and MAP2 (Neomarkers, Fremont, CA, USA) for $1 \mathrm{~h}$ at $37^{\circ} \mathrm{C}$. After a series of washes with PBS- $0.05 \%$ Triton X-100, a secondary antibody conjugated to FITC (ZyMed, San Fransisco, CA, USA), was applied and just prior to microscopic examination the cell nuclei were stained with 4'-6diamidino-2-phenylindole (DAPI). All slide images were acquired by using a Nikon Ti 200 laser scanning confocal microscope.

\section{Statistical analysis}

The data were expressed as means \pm S.E.M. One way ANOVA followed by the LSD post hoc test was done for multiple group comparisons of the data collected. $P$ values $<0.05$ were considered statistically significant. Statistical analysis was performed using SPSS 17.0.

\section{Results}

The effects of senegenin on A $\mathrm{A}$-induced cytotoxicity of PC 12 cells

MTT was used to determine the effects of senegenin on the cell viability of PC 12 cells after $A \beta$-induced cytotoxicity. Following a $24 \mathrm{~h}$ incubation period with $10 \mu \mathrm{M} \mathrm{A} \beta_{(25-35)}$ cell viability was significantly reduced (Fig. 2) compared with control. Cells pre-incubated with senegenin for $24 \mathrm{~h}$ before introducing $A \beta$ significantly increased cell viability, in dose-dependent manners as previously described [43]. When administered at concentrations of $40 \mu \mathrm{g} / \mathrm{ml}$ and $20 \mu \mathrm{g} / \mathrm{ml}$ senegenin significantly attenuated $\mathrm{A} \beta$ cytotoxicity (Fig. 2), increasing cell viability $23 \%$ and $34 \%$, respectively. These results demonstrate the cytoprotective capabilities of senegenin against $\mathrm{A} \beta$ cytotoxicity. In addition, ginsenoside Rg1 attenuated cytotoxicity up to $21 \%$ (data not shown). Comparatively, this shows that senegenin offers greater cellular protection than $\operatorname{Rg} 1$, a commonly employed derivative (ginsenoside) of Panax ginseng that has shown to effectively attenuate $A \beta$-induced cytotoxicity in numerous experiments [44-46].

\section{Morphological observation of senegenin neurite protection upon NGF removal}

Observational analysis conducted by microscope confirmed that senegenin can protect neurites of differentiated PC 12 cells from the removal of NGF (reverting from DM back to culture medium). Cells grown for 10 days in DM showed long neuritic outgrowth (Fig. 3a); however, subsequent removal of NGF lead to retraction of neurites. $48 \mathrm{~h}$ after the removal of NGF differentiated PC 12 cells retrogressed to the proliferating stage with substantial cell clumping, and fragmented and atrophied neurites (Fig. 3b).

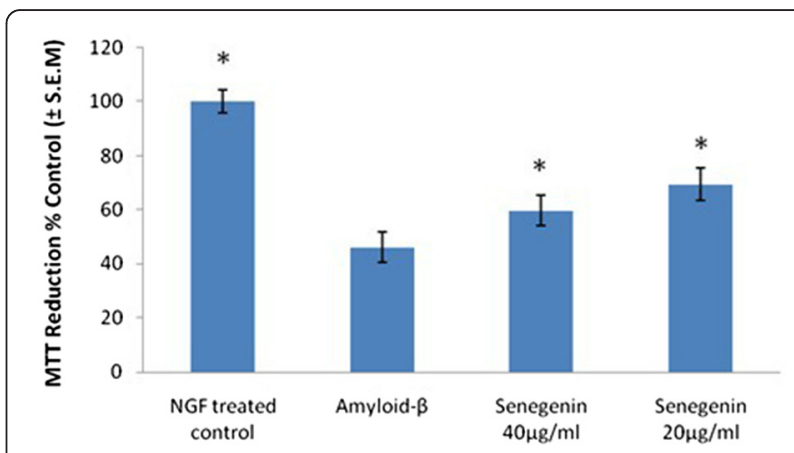

Fig. 2 Effects of senegenin on MTT levels in A $\beta$-induced cytotoxicity in PC 12 cells. The cells were incubated for $24 \mathrm{~h}$ at $37^{\circ} \mathrm{C}$ in the absence (Control \& A 3 ) or in the presence of senegenin (concentrations of $20 \mu \mathrm{g} / \mathrm{ml} \& 40 \mu \mathrm{g} / \mathrm{ml}$ ), and then incubated for $24 \mathrm{~h}$ followed by incubation with $A \beta$ for $24 \mathrm{~h}$. The data are the means \pm S.E.M. of three separate experiments performed in triplicate. Cell viability (\%) was expressed as a percentage relative to the NGF-treated control. ${ }^{*} P<0.001$ vs. Amyloid- $\beta$ treatment group 


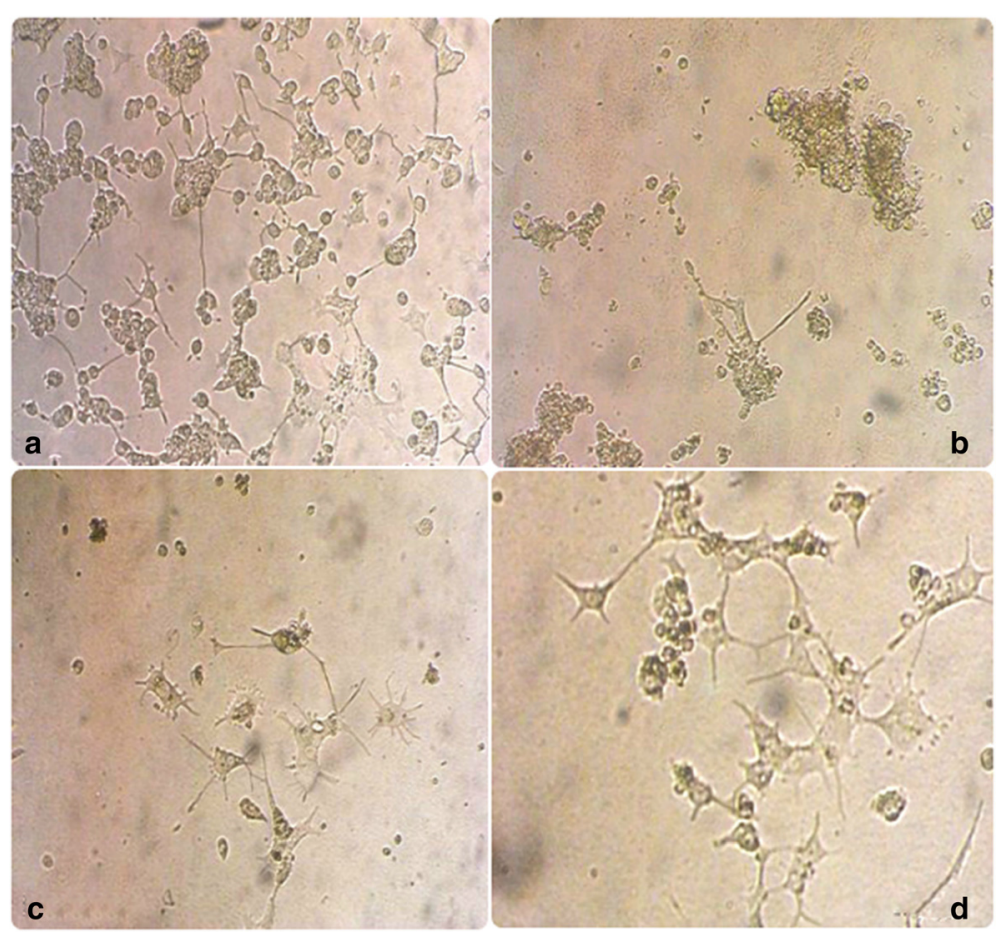

Fig. 3 Morphological examination of PC 12 cells with or without senegenin. a represents PC 12 cells after 7 days incubation with DM (NGF $100 \mathrm{ng} / \mathrm{ml}$ ). $48 \mathrm{~h}$ after the removal of DM, PC 12 cells loose neuritic processes and begin to proliferate (b). After the removal of DM, $5 \mu \mathrm{g} / \mathrm{ml}$ senegenin was added to the well. Morphological examination shows decreased axonal atrophy suggesting a neuroprotective effect (c). $\mathbf{d}$ illustrates retained neurite growth in the presence of $5 \mu \mathrm{g} / \mathrm{ml}$ senegenin $48 \mathrm{~h}$ after removal of DM

Cells that were treated with senegenin $(5 \mu \mathrm{g} / \mathrm{ml})$ retained greater neurite distribution, length and number (Fig. 3c, d); thus, morphologically demonstrating the neuroprotective efficacy of senegenin on neurites.

\section{Neuritogenic efficacy of senegenin in A $\beta$-induced neuritic degeneration}

PC 12 cells were cultured in the presence of $100 \mathrm{ng} / \mathrm{ml}$ $\beta$-NGF for 7 days to allow for significant differentiation (neurite outgrowth). After 7 days, half of the medium was changed which included the introduction of $10 \mu \mathrm{m}$ $\mathrm{A} \beta{ }_{(25-35)}$ into the DM for 4 days. Following 4 days of incubation differentiated PC 12 cells were fixed and labeled with primary antibodies for Gap- 43 and MAP2 as neurite growth markers. $A \beta$ drastically decreased total Gap-43 neurite values $(P<0.001)$, quantity $50 \%$ of control, average length $41 \%$ of control, and maximum length $65 \%$ of control, (see Figs. 4a and 5a-b). Moreover, $\mathrm{A} \beta$ reduced MAP2 neurite values $(P<0.001)$ quantity $38 \%$ of NGF positive control, average length $56 \%$ of control and maximum length $35 \%$ of control (see Figs. $4 \mathrm{~b}$ and $5 c-d)$, showing that $A \beta_{(25-35)}$ induced significant neuritic atrophy.

Thereafter, the neuritogenic effect of senegenin in PC 12 cells was explored. PC 12 cells were grown in DM for 7 days, after which $A \beta{ }_{(25-35)}$ was introduced into the medium for an additional 4 days. Next, the medium was removed and replaced with fresh medium (DM) with or without (only NGF100 ng/ml) the presence of senegenin $(1 \mu \mathrm{g} \& 5 \mu \mathrm{g} / \mathrm{ml})$. The doses were chosen as a mean variance in reference to similar experimental results [47]. After 4 days treatment the cells were fixed and immunostained with Gap-43 and MAP2 as neuritic markers. The total quantity, average length, and maximum lengths were measured against $A \beta_{(25-35)}$ control with marked decreases in A $\beta$-treated cells (see Figs. 4c-e and $5 \mathrm{~b}, \mathrm{~d})$. Treatment with senegenin significantly increased neurite outgrowth/regeneration in PC 12 cells in a concentration-dependent manner $(P \leq 0.01)$ Table 1 . At concentrations exceeding $10 \mu \mathrm{g} / \mathrm{ml}$ senegenin did not significantly increase neuritogenesis (data not shown). Whereas, at concentrations of $1 \mu \mathrm{g} / \mathrm{ml}(P<0.01)$ and $5 \mu \mathrm{g} / \mathrm{ml}(P<0.05)$ senegenin triggered neuritogenesis showing marked increases in total neurite number, average length and maximum length (see Figs. 4c-d and $5 \mathrm{e}-\mathrm{f}, \mathrm{i})$. Notably, the use of NGF alone to trigger regeneration after administration of $A \beta$ did not significantly regenerate neurites compared to senegenin treatment or A $\beta$ control (Figs. 4c-e, 5g, h). The use of NGF has shown to induce neurite growth in cortical neurons and PC 12 cells so its neuritogenic efficacy was measured against dose-dependent concentrations of senegenin 


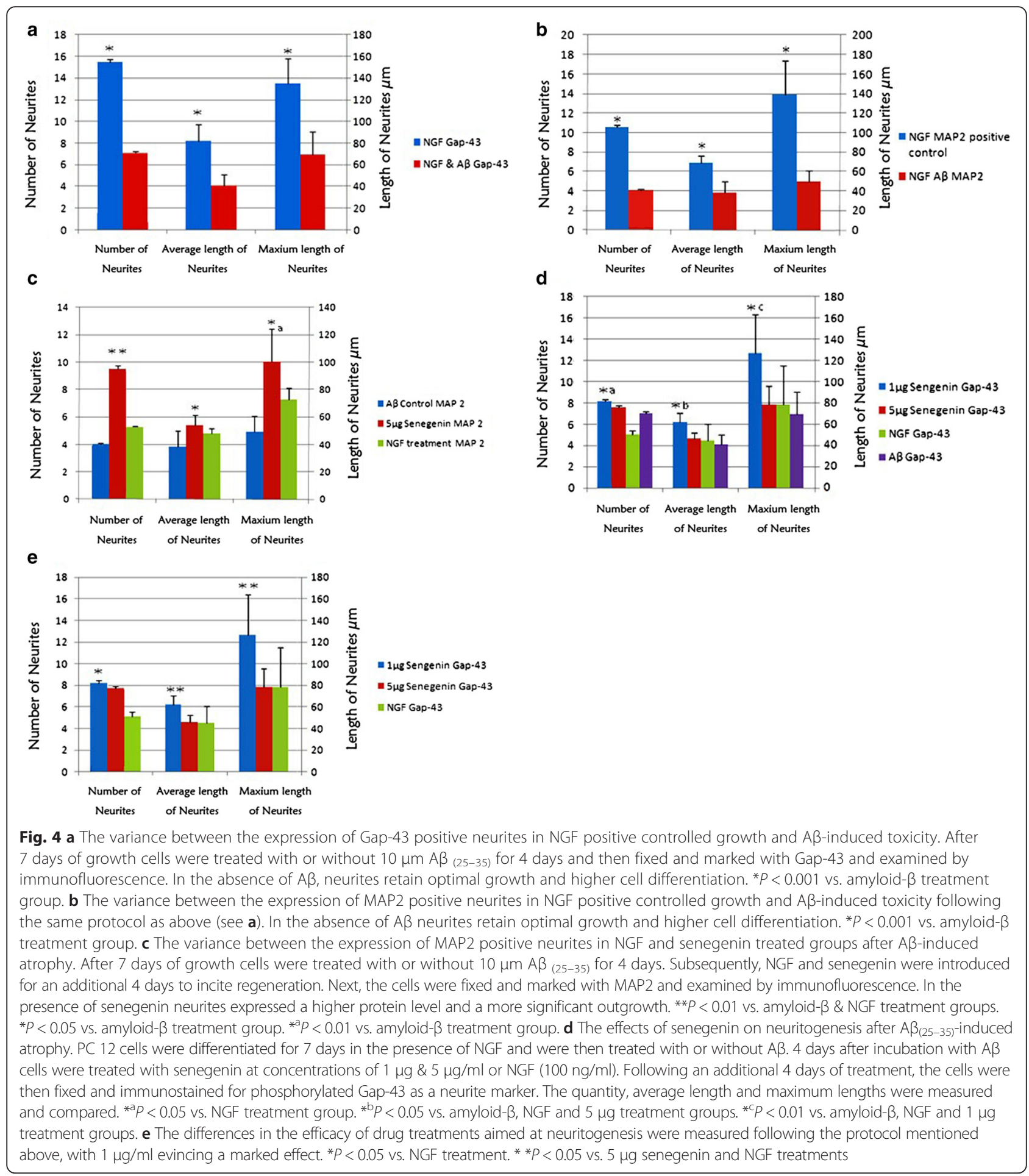

wherein, of the concentrations utilized, it showed that $1 \mu \mathrm{g} / \mathrm{ml}$ (Fig. 4e) was the most effectual $(P<0.05)$ (Table 1).

\section{Discussion}

Severe neuronal atrophy with neuritic degeneration is a common pathogenic characteristic of neurodegenerative disorders. The possibility of regeneration presents to be of cardinal significance in abating neurodegeneration. To date, in vivo and in vitro experiments have demonstrated that axonal, dendritic and synaptic regeneration are possible $[42,46,48-50]$. One postulate that facilitates the regeneration of neuronal structures is the intracellular signaling proteins attributable to neural plasticity; possibilities that 

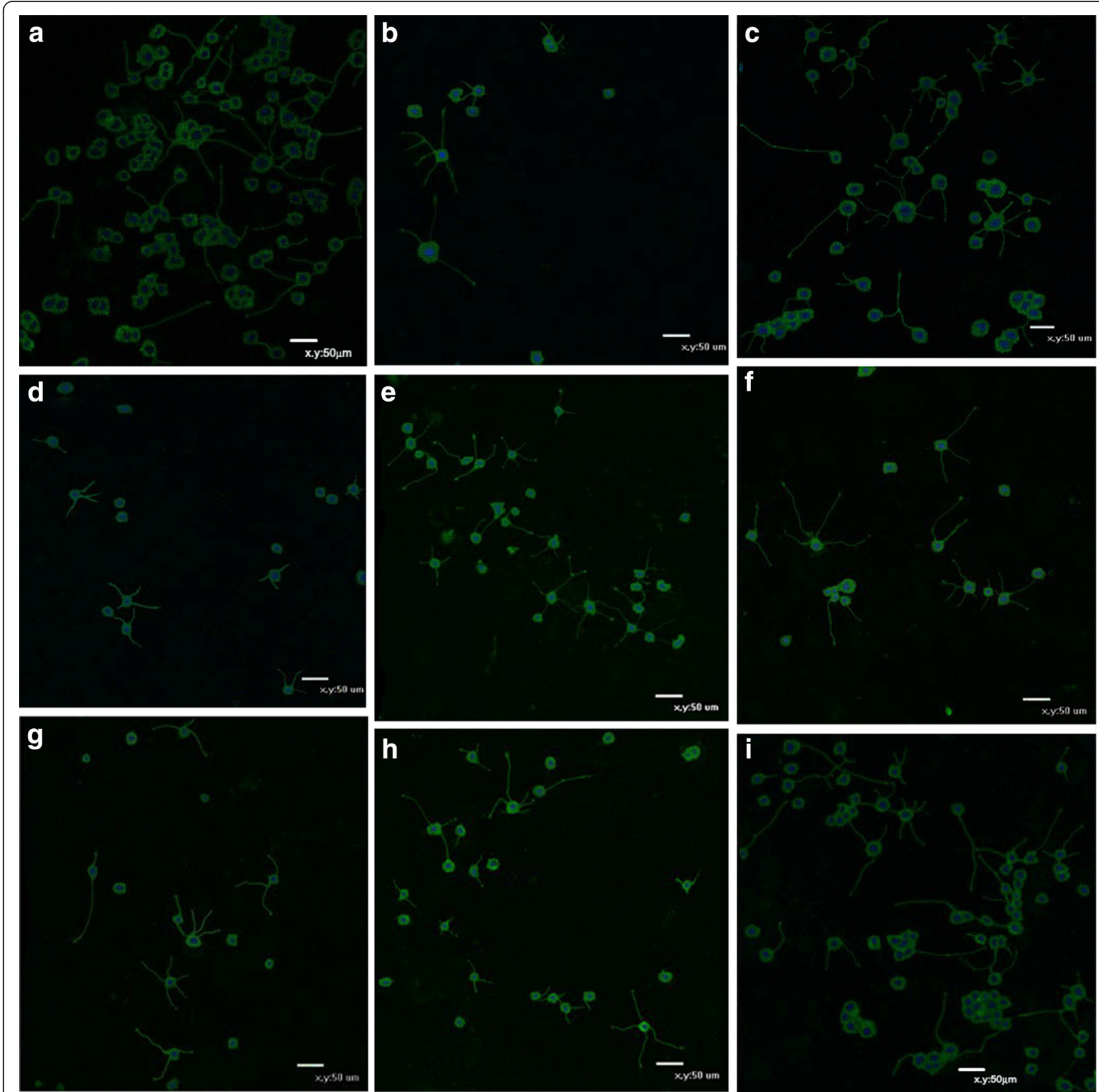

Fig. 5 a-i displaying the effects of NGF, Aß-induced neurite atrophy and neuritogenic outcomes of senegenin. a PC 12cells after 7 days of NGFinduced neurite outgrowth with positive expression of Gap-43. b Aß-induced axonal atrophy and cell loss with additional reduction in Gap-43 expression. PC 12 cells were differentiated in DM for 7 days, thereafter A $\beta$ was administered for 4 days. $\mathbf{c}$ PC 12 cells immunostained with MAP2 7 days after NGF-induced differentiation. $\mathbf{d} P C 12$ cells were differentiated in DM for 7 days with subsequent incubation in the presence of $A \beta$ for 4 days, then immunostained with MAP2 as a neurite marker. e Neuritogenic effect of senegenin $(5 \mu \mathrm{g} / \mathrm{ml})$ after 4 days of AB-induced atrophy. PC 12 cells show increased neurite outgrowth and MAP2 expression. $\mathbf{f}$ Neuritogenic effect of senegenin $(5 \mu \mathrm{g} / \mathrm{ml})$ after 4 days of AB-induced atrophy. PC 12 cells show increased neurite outgrowth and Gap-43 expression. $\mathbf{g}$ Neuritogenic effect of NGF (100 ng/ml) after 4 days of AB-induced atrophy. PC 12 cells show little neurite outgrowth w/ MAP2 expression. $\mathbf{h}$ Neuritogenic effect of NGF $(100 \mathrm{ng} / \mathrm{ml})$ after 4 days of A -induced atrophy. PC 12 cells show moderate neurite outgrowth w/ Gap-43 expression. i Neuritogenic outcome in the presence of senegenin (1 $\mu \mathrm{g} / \mathrm{ml})$ after 4 days of A -induced atrophy. PC 12 cells show increased neurite outgrowth w/ Gap-43 expression

may be innate to the mammalian brain, but are somewhat repressed in the adult brain. Although under the influence of nootropic agents and neurotrophins they may become reactivated leading to neurito-and-synaptogenesis.
The aim of this present study was to evaluate the cytoprotective and neuritogenic/regenerative potential of senegenin. Cell viability, a valuable indication of mitochondrial function and integral to cellular differentiation, 
Table 1 The changes in neurite composition under the influence of A $\beta$-induced degeneration and drug treatments

\begin{tabular}{lccr}
\hline Treatments \& protein expression & Neurite quantity & Average length & Maximum length \\
\hline NGF positive control w/ Gap-43 & $15.5 \pm 2.38^{*}$ & $81.75 \pm 15.33^{*}$ & $134.75 \pm 22.91^{*}$ \\
NGF positive control w/MAP2 & $10.5 \pm 1.29^{*}$ & $68.75 \pm 7.23^{*}$ & $139.0 \pm 34.42^{*}$ \\
Amyloid- $\beta$ w/Gap-43 & $7.0 \pm 1.83$ & $41.0 \pm 9.63$ & $69.5 \pm 21.25$ \\
NGF control w/MAP2 & $5.25 \pm 0.957$ & $48.0 \pm 3.56$ & $73.5 \pm 8.18$ \\
Amyloid- $\beta$ w/MAP2 & $4.0 \pm 0.826$ & $38.25 \pm 11.44$ & $49.25 \pm 11.27$ \\
Senegenin $5 \mu \mathrm{g}$ w/Gap-43 & $7.75 \pm 1.71$ & $46.5 \pm 5.8$ & $78.25 \pm 17.35$ \\
Senegenin $5 \mu \mathrm{g}$ w/MAP2 & $9.5 \pm 2.38^{*}$ & $54.25 \pm 7.04^{*}$ & $100.5 \pm 24.15^{*}$ \\
Senegenin $1 \mu \mathrm{g}$ w/Gap-43 & $8.25 \pm 1.71^{*}$ & $62.25 \pm 8.06^{*}$ & $126.75 \pm 36.86^{*}$ \\
NGF treatment w/Gap-43 & $5.0 \pm 3.56$ & $45.0 \pm 15.64$ & $78.5 \pm 36.74$ \\
\hline
\end{tabular}

Cells were grown for 7 days in the presence of DM, followed by 4 days incubation with $A \beta_{(25-35)}$ peptide. The medium was then changed to include various concentrations of drugs for an additional 4 days to allow for neurite outgrowth. PC 12 cells were then fixed and labeled with primary antibodies

${ }^{*} P<0.01$ vs. Amyloid- $\beta$ treatment group

signaling and growth [51] was chosen to test the neurotoxic properties of $A \beta$. $A \beta$ (25-35), a commonly employed neurotoxic peptide [52-55], decreased cell viability by $\sim 60 \%$. Interestingly, senegenin, at dose-dependent concentrations $(20 \mu \mathrm{g}$ and $40 \mu \mathrm{g} / \mathrm{ml})$, attenuated $\mathrm{A} \beta$ toxicity and significantly increased cell viability in differentiated PC 12 cells. A $\beta$-induced neurotoxicity is thought to be partially caused by the induction of apoptotic pathways [56] and proapoptotic factors such as reactive oxygen species (ROS), endoplasmic reticulum (ER) stress and nitric oxide $(\mathrm{NO})$. Research has shown that $\mathrm{A} \beta$ targets the apoptosis signal-regulating kinase 1 (ASK1) - JNK pathway $[57,58]$ which, through the production of ROS, constitutes a major apoptotic signaling pathway. In PC 12 cells, $A \beta$-induced cell death results from ROS-mediated activation of ASK1, which is independent of the ER stress pathway [57]. Caspase-2 has also been implicated in the induction of $\mathrm{A} \beta$-induced apoptotic cell death in several neuronal populations including PC 12 [58]. In addition, c-Jun N-terminal kinase (JNK), which is activated by $A \beta$, plays a crucial role in triggering Fas ligand death factors that in turn leads to the binding of Fas ligand to its receptor Fas, and subsequently to the activation of a caspase cascade [59]; thus supporting the implicated role of caspase- 2 in apoptotic cell death. Based on the activation of the JNK pathway and the following cellular cascades induced by $A \beta$ one possible mechanism by which senegenin exhibits its cytoprotective qualities is through inhibition of ASK1 and/or JNK pathways. Additional support for this postulate can be found in the prevention of apoptosis in NGFdeprived PC 12 cells through inhibition of JNK or c-Jun [59]. Although evidence supports this mechanism of action further research is required to delineate the potential relationship of senegenin and the JNK pathway.

The attributes of neural plasticity, which encompass neuritogenesis, are proving to be a promising avenue of exploration by elucidating the complexities of the neuronal framework; from which new therapeutic angles have begun to arise. From this perspective, the neuritogenic potential of senegenin was examined. Results showed that at dose-dependent concentrations $(1 \mu \mathrm{g}$ and $5 \mu \mathrm{g} / \mathrm{ml}$ ) neurite outgrowth/regeneration was potentiated. The induction of neurite growth requires the coordinate expression of certain growth proteins such as Gap-43 and MAP2, both of which, in comparison to A $\beta$ treated groups, were up-regulated after introduction of senegenin. These results are in agreement with previous studies that demonstrated that during times of regeneration Gap-43 expression rises, and is essential to neurite formation where it is expressed in along the entire axon $[60,61]$, with the progression of neuritogenesis shifting the concentration of Gap-43 to more distal locations; notably, growth cones and synaptic regions [61]. Moreover, in the absence of Gap-43 via the introduction of anti-Gap-43 antibodies neuritogenesis is prevented [60]. Gap-43 is a phospho-protein and a major substrate of protein kinase $\mathrm{C}$ (PKC), which implies that Gap-43 regulation of growth cones relies on a correlative relationship with PKC-induced phosphorylation [62, 63]. Furthermore, diacylglycerols (DAGs) an endogenous activator of PKC has shown to induce neuritogenesis in ganglia explants [64]. In concurrence with the relationship between PKC, neurite outgrowth and Gap-43, one likely mechanism of action for the neuritogenic efficacy of senegenin is its possible stimulation of PKC, leading to increased phosphorylation of Gap-43, and therefore to the initiation of growth cone formation and enhanced neurite outgrowth. This postulate is concordant with Yankner et al. [65] results that demonstrated marked acceleration in initial neurite growth and greater sensitivity to NGF in PC 12 cells expressing higher levels of Gap-43. PKC has additionally been found to phosphorylate MAP2, which is associated with decreased 
cytoskeletal stability [66]. Conversely, dephosphorylation of MAP2 is predicted to have an inverse reaction, thereby promoting cytoskeletal stabilization. Such a change in phosphorylated states leads to the instability of microtubules, which in turn corresponds with neurite outgrowth in hippocampal neurons [67]. Previous studies have noted that MAPs are imperative to cytoskeletal regulation and neurite growth [17], especially in dendritic development where MAP2 is heavily enriched [68] and goes through various phosphorylated states [69] that are in part regulated by PKC $[66,70]$. From this, some reasonable inferences can be made regarding senegenin's mechanisms of action. One, since MAP2 goes through alternating states of phosphorylation inducing oscillations of stability within microtubules, which allows for neuritic formation and outgrowth the mobilization of MAPs must be integral to the growth stage in PC 12 cells. Two, while the activation of MAP2 is important for PC 12 differentiation there appears to be little correlation between NGF and PKCinduced phosphorylation of MAP2 [71], suggesting that the activation of MAP2 is not a result of NGF-induced activation of PKC. We then speculate that if senegenin triggers $\mathrm{PKC}$ and phosphorylation of MAP2 this would lead to a notable increase in neurite growth as demonstrated in this study. Correspondingly, the increased protein recognition of Gap-43 and MAP2 by immunfluorescence in differentiated PC 12 cells found in this experiment is concordant with the associative mechanisms of action and imperative roles that these proteins play in neuritic development and formation.

While it is worth noting that the neurite outgrowth elicited by senegenin may have been produced through potentiating NGF-induced outgrowth, results demonstrated that in the sole presence of senegenin (Fig. 3c-d) neurite outgrowth was maintained. We thus propose that the results elicited herein stemmed from senegenin's effects on PKC and phosphorylation of MAP2 rather than potentiating NGF.

\section{Conclusion}

Dysfunctional protein assembly precipitates the occurrence of neurodegenerative illnesses like $\mathrm{AD}$ through abnormal accumulation. A prototypical example is the neurotoxic peptide $A \beta$. Two of most significant corollaries of misfolded proteins are dystrophic neurites and neuronal atrophy. This implies that to effectively tackle neurodegenerative diseases desired therapeutics need to possess neuroprotective and neuritogenic capacities. A promising source of such potential therapeutics can be found in botanical medicines. P. tenuifolia has empirically shown to be efficacious in treating cognitive disorders, and was thus a fitting choice for exploration of neuroprotective and neuritogenic potential. The results generated in our study suggest that senegenin not only possesses cytoprotective, and neuritogenic properties, but that it can also augment the expression of cardinal growth proteins vital to neural plasticity. One possible mechanism by which senegenin exhibits its cytoprotective qualities is through inhibition of ASK1 and/or JNK pathways. While deducing the exact neuritogenic mechanisms of action went outside of our studies aim, concordant studies lead us to hypothesize that these results stemmed from senegenin's activation of PKC and its phosphorylation of MAP2. Although these results are in agreement with other literature surrounding the neuritogenic and neuroprotective nature of P. tenuifolia, further research is required to elucidate senegenin's exact neurogenic mechanisms and its full therapeutic range. All in all, these results continue to support and illuminate P. tenuifolia's (i.e., senegenin) salubrious potential, and suggest it may be efficacious in the treatment of neurodegenerative disorders.

\section{Abbreviations \\ AD: Alzheimer's disease; ASK1: apoptosis signal-regulating kinase 1: $A \beta$ : amyloid- $\beta$; DAGs: diacylglycerols; DM: differentiating medium; DMEM: Dulbecco's Modified Eagle Medium; ER: endoplasmic reticulum; Gap-43: growth associated protein 43; JNK: c-Jun N-terminal kinase; MAP: microtubule-associated protein; MAPK: mitogen-activated protein kinases; MTT: (3,4,5-dimethylthiazol-2-yl)2,5-diphenyltetrazolium bromide; NFT: neurofibrillary tangles; NGF: nerve growth factor; NO: nitric oxide; PC 12: pheochromocytoma cell line; PKC: protein kinase $C_{;}$ROS: reactive oxygen species.}

\section{Competing interests}

The authors declare that they have no competing interests.

\section{Authors' contributions}

RJ conceptualized, designed and performed the experiments. CHL supervised the design of the study. RJ collected data and CHL interpreted and supervised the analysis of the data. CHL provided reagents, contributed to confocal microscopy, and critically reviewed drafted manuscript. RJ wrote the paper and carried out revisions. Both authors have read and approved the final manuscript.

\section{Acknowledgements}

The authors would like to thank Prof. Lv Shen for the warm welcome into his laboratory and the positive working environment. Moreover, we thank Dr. Li Mei for sharing knowledge on relevant protocols within the lab. Lastly, we would like to express our gratitude to Dr. Yuan Xiaolin at the Zhong Shan (Tie Lu) hospital for granting access to his lab and offering the kind use of their confocal microscope.

Received: 9 March 2015 Accepted: 20 January 2016

Published online: 23 January 2016

\section{References}

1. Taylor JP, Hardy T, Fischbeck KH. Toxic Proteins in Neurodegenerative Disease. Science. 2002;296(5575):1991-5.

2. Selkoe DJ. Alzheimer's Disease: genes, proteins, and therapy. Physiol Rev. 2001;81(2):741-66

3. Hardy J, Selkoe DJ. The amyloid hypothesis of Alzheimer's disease: progress and problems on the road to therapeutics. Science. 2002;297:353-6.

4. Lambert MP, Barlow AK, Chromy BA, Edwards C, Freed R, Liosatos M, et al. Diffusible, nonfibrillar ligands derived from Abeta1-42 are potent central nervous system neurotoxins. Proc Natl Acad Sci U S A. 1998;95(11):6448-53.

5. Selkoe DJ. Alzheimer's disease is a synaptic failure. Science. 2002;298(5594):789-91.

6. Glabe CG. Common mechanisms of amyloid oligomer pathogenesis in degenerative disease. Neurobiol Aging. 2006;27(4):570-5. 
7. Lacor PN, Buniel MC, Chang L, Fernandez SJ, Gong Y, Viola KL, et al. Synaptic Targeting by Alzheimer's-Related Amyloid- $\beta$ Oligomers. J Neurosci. 2004;24(45):10191-200.

8. Ferri $C P$, Prince $M$, Brayne C, Brodaty $H$, Fratiglioni L, Ganguli M, et al. Alzheimer's Disease International: Global prevalence of dementia: a Delphi consensus study. Lancet. 2005;366(9503):2112-7.

9. Greene LA, Tischler AS. Establishment of a noradrenergic clonal line of rat adrenal pheochromocytoma cells with respond to nerve growth factor. Proc Natl Acad Sci U S A. 1976;73(7):2424-8.

10. Pollock JD, Krempin M, Rudy B. Differential effects of NGF, FGF, EGF, CAMP, and dexamethasone on neurite outgrowth and sodium channel expression in PC12 cells. J Neurosci. 1990;10(8):2626-37.

11. Brugg B, Matus A. PC 12 cells express juvenile microtubule-associated proteins during nerve growth factor-induced neurite growth. J Cell Biol. 1988;107(2):643-50.

12. Karns LR, Ng SC, Freeman JA, Fishman MC. Cloning of complementary DNA for GAP-43, a neuronal growth-related protein. Science. 1987;236(4801):597-600.

13. Van Hooff CO, De Graan PN, Oestreicher AB, Gispen WH. B-50 phosphorylation and polyphosphoinositide metabolism in nerve growth cone membranes. J Neurosci. 1988;8(5):1789-95.

14. Meiri KF, Pfenninger KH, Willard MB. Growth-associated protein, GAP-43, a polypeptide that is induced when neurons extend axons, is a component of growth cones and corresponds to $\mathrm{pp} 46$, a major polypeptide of a subcellular fraction enriched in growth cones. Proc Natl Acad Sci U S A. 1986;83(10):3537-41.

15. Costello B, Meymandi A, Freeman JA. Factors Influencing GAP-43 Gene Expression in PC1 2 Pheochromocytoma Cells. J Neurosci. 1990;10(4):1396-406.

16. Yamada KM, Spooner BS, Wessells NK. Axon growth: role of microfilaments and microtubules. Proc Natl Acad Sci U S A. 1970;66(4):1206-12.

17. Seeds NW, Gilman AG, Amano T, Nirenberg MW. Regulation of axon formation by clonal lines of neural tumor. Proc Natl Acad Sci U S A. 1970;66(1):160-7.

18. Sánchez C, Díaz-Nido J, Avila J. Variations in in viva phosphorylation at the proline-rich domain of the microtubule-associated protein 2 (MAP2) during rat brain development. J Biochem. 1995;306:481-7.

19. Sánchez C, Díaz-Nido J, Avila J. Phosphorylation of microtubule-associated protein 2 (MAP2) and its relevance for the regulation of the neuronal cytoskeleton function. Prog Neurobiol. 2000;61(2):133-68.

20. Pang L, Sawada T, Decker SJ, Saltiel AR. Inhibition of MAP kinase kinase blocks the differentiation of PC-12 cells induced by nerve growth factor. J Biol Chem. 1995;270:13585-8.

21. Cáceres A, Banker GA, Binder L. Immunocytochemical Localization of Tubulin and Microtubule-Associated Protein 2 During the Development of Hippocampal Neurons in Culture. J Neurosci. 1986;6(3):714-22.

22. Jahn R, Schiebler W, Ouimet C, Greengard P. A 38,000-dalton membrane protein (p38) present in synaptic vesicles. Proc Natl Acad Sci U S A. 1985;82(12):4137-41.

23. Nieto-Sampedro M, Nieto-Díaz M. Neural Plasticity: changes with age. J Neural Transm. 2005;112(1):3-27

24. Burke SN, Barnes CA. Neural plasticity in the ageing brain. Nature Rev Neurosci. 2006;7:30-40

25. Kempermann G, Kuhn HG, Gage FH. More hippocampal neurons in adult mice living in an enriched environment. Nature. 1997;386(6624):493-5.

26. Eriksson PS, Perfilieva E, Björk-Eriksson T, Alborn AM, Nordborg C, Peterson DA, et al. Neurogenesis in the adult human hippocampus. Nat Med. 1998;4(11):1313-7.

27. Kromer LF. Nerve growth factor treatment after brain injury prevents neuronal death. Science. 1987;235(4785):214-6.

28. Prakash N, Cohen-Cory S, Penschuck S, Frostig RD. Basal forebrain cholinergic system is involved in rapid nerve growth factor (NGF)-induced plasticity in the barrel cortex of adult rats. J Neurophysiol. 2004;91(1):424-37.

29. Patapoutian A, Reichardt LF. Trk receptors: mediators of neurotrophin action. Curr Opin Neurobiol. 2001;11(3):272-80.

30. McAllister AK, Katz LC, Lo DC. Neurotrophins and synaptic plasticity. Annu Rev Neurosci. 1999:22:295-318.

31. Friden PM, Walus LR, Watson P, Doctrow SR, Kozarich JW, Backman C, et al. Blood-brain barrier penetration and in vivo activity of an NGF conjugate. Science. 1993;259(5093):373-7.

32. Bäckman C, Rose GM, Hoffer BJ, Henry MA, Bartus RT, Friden P, et al. Systemic administration of a Nerve Growth Factor Conjugate Reverses
Age-Related Cognitive Dysfunction and Prevents Cholinergic Neuron Atrophy. J Neurosci. 1996;16(17):5437-42.

33. Yamada K, Nitta A, Hasegawa T, Fuji K, Hiramatsu M, Kameyama T, et al. Orally active NGF synthesis stimulators: potential therapeutic agents in Alzheimer's disease. Behav Brain Res. 1997;83(1-2):117-22.

34. Pardridge WM. The Blood-brain Barrier: Bottleneck in Brain Drug Development. NeuroRx. 2005;2(1):3-14.

35. Liu WB, Liu WZ. Disciplinarian investigation of Chinese complex prescription with promoting intelligence in past dynasties. Jiangxi J Traditional Chin Med. 2005;36:62-3.

36. Park CH, Choi SH, Koo JW, Seo JH, Kim HS, Jeong SJ, et al. Novel cognitive improving and neuroprotective activities of Polygala tenuifolia Willdenow extract, BT-11. J Neurosci Res. 2002:70(3):484-92.

37. Karakida F, Ikeya Y, Tsunakawa M, Yamaguchi T, Ikarashi Y, Takeda S, et al. Cerebral Protective and Cognition-Improving Effects of Sinapic Acid in Rodents. Biol Pharm Bull. 2007;30(3):514-9.

38. Jia $H$, Jiang $Y$, Ruan $Y$, Zhang $Y$, Ma $X$, Zhang J, et al. Tenuigenin treatment decreases secretion of the Alzheimer's disease amyloid- $\beta$ protein in cultured cells. Neurosci Lett. 2004;367(1):123-8.

39. LV J, Jia H, Jiang Y, Ruan Y, Liu Z, Yue W, et al. Tenuifolin, an extract derived from tenuigenin, inhibits amyloid- $\beta$ secretion in vitro. Acta Physiol (Oxf). 2009;196(4):419-25.

40. Zhang H, Han T, Zhang L, Yu CH, Wan DG, Rahman K, et al. Effects of tenuifolin extracted from radix polygalae on learning and memory: $\mathrm{A}$ behavioral and biochemical study on aged and amnesic mice. Phytomedicine. 2008;15(8):587-94.

41. Yabe $T$, Tuchida H, Kiyohara $H$, Takeda $T$, Yamada $H$. Induction of NGF synthesis in astrocytes by onjisaponins of Polygala tenuifolia constituents of kampo (Japanese herbal) medicine Ninjin-yoei-to. Phytomedicine. 2003;10(2-3):106-14.

42. Park HJ, Lee K, Heo H, Lee M, Kim JW, Whang WW, et al. Effects of Polygala tenuifolia Root Extract on Proliferation of Neural Stem Cells in the Hippocampal CA1 Region. Phytother Res. 2008;22(10):1324-9.

43. Ban JY, Cho SO, Koh SB, Song KS, Bae K, Seong YH. Protection of amyloid beta protein (25-35)-induced neurotoxicity by methanol extract of Smilacis chinae rhizome in cultured rat cortical neurons. J Ethnopharmacol. 2006;106(2):230-7.

44. Qian $\mathrm{YH}, \mathrm{Han} \mathrm{H}, \mathrm{Hu} X \mathrm{X}$, Shi LL. Protective effect of ginsenoside Rb1 on $\beta$-amyloid protein (1-42)-induced neurotoxicity in cortical neurons. Neurol Res. 2008:31:663-7.

45. Sano M, Grossman H, Van Dyk K. Preventing Alzheimer's disease separating fact from fiction. CNS Drugs. 2008;22:887-902.

46. Tohda C, Matsumoto N, Zou K, Meselhy MR, Komatsu K. Abeta(25-35)induced memory impairment, axonal atrophy, and synaptic loss are ameliorated by M1, A metabolite of protopanaxadiol-type saponins. Neuropsychopharmacology. 2004;29(5):860-8.

47. Kim JH, Ha HC, Lee MS, Kang Jl, Kim HS, Lee SY, et al. Effect of Tremella fuciformis on the Neurite Outgrowth of PC12h Cells and the Improvement of Memory in Rats. Biol Pharm Bull. 2007:30(4):708-14.

48. Cui L, Locatelli L, Xie MY, Sommadossi JP. Effect of Nucleoside Analogs on Neurite Regeneration and Mitochondrial DNA Synthesis in PC-12 Cells. J Pharmacol Exp Ther. 1997;280(3):1228-34.

49. Kuboyama T, Tohda C, Komatsu K. Neuritic regeneration and synaptic reconstruction induced by withanolide $\mathrm{A}$. Br J Pharmacol. 2005;144(7):961-71.

50. Tohda C, Tamura T, Matsuyama S, Komatsu K. Promotion of axonal maturation and prevention of memory loss in mice by extracts of Astragalus mongholicus. Br J Pharmacol. 2006;149(5):532-41.

51. Murphy AN, Fiskum G, Beal MF. Mitochondria in neurodegeneration: bioenergetic function in cell life and death. J Cereb Blood Flow Metab. 1999;19(3):231-45.

52. Hensley K, Carney JM, Mattson MP, Aksenova M, Harris M, Wu JF, et al. A model for 3-amyloid aggregation and neurotoxicity based on free radical generation by the peptide: Relevance to Alzheimer disease. Proc Natl Acad Sci U S A. 1994;91(8):3270-4.

53. Shearman MS, Ragan Cl, Iversen LL. Inhibition of PC12 cell redox activity is a specific, early indicator of the mechanism of 1-amyloid-mediated cell death. Proc Natl Acad Sci U S A. 1994:91(4):1470-4

54. Hughes E, Burke RM, Doig AJ. Inhibition of Toxicity in the $\beta$-Amyloid Peptide Fragment $\beta$-(25-35) Using N-Methylated Derivatives: a general strategy to prevent amyloid formation. J Biol Chem. 2000;275(33):25109-15. 
55. Nishida H, Kushida M, Nakajima Y, Ogawa Y, Tatewaki N, Sato S, et al. Amyloid- $\beta$-Induced Cytotoxicity of PC-12 Cell Was Attenuated by Shengmai-san Through Redox Regulation and Outgrowth Induction. J Pharmacol Sci. 2007;104(1):73-81.

56. Troy CM, Rabacchi SA, Friedman WJ, Frappier TF, Brown K, Shelanski ML. Caspase-2 mediates neuronal cell death induced by $\beta$-Amyloid. J Neurosci. 2000;20(4):1386-92.

57. Kadowaki H, Nishitoh H, Urano F, Sadamitsu C, Matsuzawa A, Takeda K, et al. Amyloid- $\beta$ induces neuronal cell death through ROS-mediated ASK1 activation. Cell Death Differ. 2005;12(1):19-24.

58. Hsu MJ, Hsu CY, Chen BC, Chen MC, Ou G, Lin CH. Apoptosis signal regulating kinase 1 in amyloid beta peptide-induced cerebral endothelial cell apoptosis. J Neurosci. 2007;27:5719-29.

59. Morishima Y, Gotoh Y, Zieg J, Barrett T, Takano H, Flavell R, et al. Betaamyloid induces neuronal apoptosis via a mechanism that involves the c-Jun $\mathrm{N}$-terminal kinase pathway and the induction of Fas ligand. J Neurosci. 2001;21(19):7551-60.

60. Shea TB, Perrone-Bizzozero NI, Beermann ML, Benowitz LI. Phospholipidmediated delivery of anti-GAP-43 antibodies into neuroblastoma cells prevents neuritogenesis. J Neurosci. 1991;11(6):1685-90.

61. Meiri KF, Willard M, Johnson MI. Distribution and Phosphorylation of the Growth-Associated Protein GAP-43 in Regenerating Sympathetic Neurons in Culture. J Neurosci. 1988;8(7):2571-81.

62. Aloyo VJ, Zwiers H, Gispen WH. Phosphorylation of B-50 protein by calciumactivated, phospholipid-dependent protein kinase and B-50 protein kinase. J Neurochem. 1983:41(3):649-53.

63. Shen Y, Mani S, Donovan SL, Schwob JE, Meiri KF. Growth-Associated Protein-43 is required for commissural axon guidance in the developing vertebrate nervous system. J Neurosci. 2002;22(1):239-47.

64. Hsu L, Jeng AY, Chen KY. Induction of neurite outgrowth from chick embryonic ganglia explants by activators of protein kinase C. Neurosci Lett. 1989;99(3):257-62.

65. Yankner BA, Benowitz LI, Villa-Komaroff L, Neve RL. Transfection of PC12 cells with the human GAP-43 gene: effects on neurite outgrowth and regeneration. Brain Res Mol Brain Res. 1990;7(1):39-44.

66. Quinlan EM, Halpain S. Emergence of activity-dependent, bidirectional control of microtubule-associated protein MAP2 phosphorylation during postnatal development. J Neurosci. 1996;16(23):7627-37.

67. Diez-Guerra FJ, Avila J. An increase in phosphorylation of microtubuleassociated protein 2 accompanies dendrite extension during the differentiation of cultured hippocampal neurons. Eur J Biochem. 1995:227(1-2):68-77.

68. Caceres A, Binder LI, Payne MR, Bender P, Rebhun L, Steward O. Different sub cellular localization of tubulin and the microtubule associated protein MAP2 in brain tissue as revealed by immunocytochemistry with monoclonal hybridoma antibodies. J Neurosci. 1984;4:394-410.

69. Brugg B, Matus A. Phosphorylation Determines the Binding of Microtubuleassociated Protein 2 (MAP2) to Microtubules in Living Cells. J Cell Biol. 1991;114(4):735-43.

70. Ainsztein AM, Purich DL. Stimulation of Tubulin Polymerization by MAP-2 J Biol Chem. 1994;269(45):28465-71.

71. Miyasaka T, Chao MV, Sherline P, Saltiel AR. Nerve growth factor stimulates a protein kinase in $\mathrm{PC}-12$ cells that phosphorylates microtubule-associated protein-2. J Biol Chem. 1990;265(8):4730-5.

\section{Submit your next manuscript to BioMed Central and we will help you at every step:}

- We accept pre-submission inquiries

- Our selector tool helps you to find the most relevant journal

- We provide round the clock customer support

- Convenient online submission

- Thorough peer review

- Inclusion in PubMed and all major indexing services

- Maximum visibility for your research

Submit your manuscript at www.biomedcentral.com/submit

) Biomed Central 